Check for updates

Cite this: RSC Adv., 2017, 7, 56204

Received 17th September 2017 Accepted 21st November 2017

DOI: $10.1039 / c 7 r a 10318 b$

rsc.li/rsc-advances

\section{Preparation of a new 2D MXene/PES composite membrane with excellent hydrophilicity and high flux}

\author{
Runlin Han, (D) *ab Xufeng Ma, ${ }^{a}$ Yongli Xie, ${ }^{a}$ Da Teng ${ }^{a}$ and Shouhai Zhang*b
}

MXene, a new 2D transition metal carbide-based material, possesses excellent electrical conductivity and hydrophilicity. In this study, $\mathrm{Ti}_{3} \mathrm{C}_{2} \mathrm{~T}_{x}$ (where $\mathrm{T}$ represents a functional group $(\mathrm{O}, \mathrm{OH}$, and/or $\mathrm{F}$ )) was produced by etching and ultrasonicating $\mathrm{Ti}_{3} \mathrm{AlC}_{2}$. Then, it was used to prepare the MXene composite membrane via a simple filtration method performed at $0.2 \mathrm{MPa}$ on a polyethersulfone (PES) ultrafiltration membrane. The MXene composite membrane shows excellent flux $\left(115 \mathrm{~L} \mathrm{~m}^{-2} \mathrm{~h}^{-1}\right)$ and favorable rejection to Congo red dye $(92.3 \%$ at $0.1 \mathrm{MPa})$. The membrane demonstrated rejection to inorganic salts below $23 \%$ with flux above $432 \mathrm{~L} \mathrm{~m}^{-2} \mathrm{~h}^{-1}$ at $0.1 \mathrm{MPa}$. Due to its loose lamellar structure, the composite membrane is able to demonstrate efficient permselectivity in the separation of dyes from salts. Furthermore, the composite membrane shows excellent hydrophilicity and flux because of the lamellar hydrophilic MXene.

\section{Introduction}

Polymer membranes have been widely used in the process of wastewater treatment and desalination due to their excellent permselectivity, mechanical properties, and relative low cost. ${ }^{1}$ In order to further improve the thermal resistance, fouling resistance and other performance parameters of such polymer membranes, substantial effort has been made including crosslinking, ${ }^{2,3}$ hydrophilic modification of membrane material ${ }^{4}$ and fabrication of mixed-matrix membranes (MMMs). ${ }^{5-7} \mathrm{~A}$ heterogeneous MMM consists of an inorganic filler embedded in a polymer matrix and combines the superior permeability and selectivity of inorganic membranes with the processability of polymeric membranes; thus, it shows great advantages in membrane-based gas separations and pervaporation. ${ }^{8}$ Graphene oxide (GO) membranes have been demonstrated to function as effective barriers for gas and liquid separations..$^{9-12}$ Several breakthroughs relating to GO-based membranes have been achieved, demonstrating that GO is a promising membrane material for gas and liquid separation because of its distinctive 2D structure. However, the flux of GO membranes is relatively low because of the small interlayer spacing that results under pressure; for example, the flux of the GO membrane in ref. 10 is about $1702 \mathrm{~g} \mathrm{~m}^{-2} \mathrm{~h}^{-1}$ under vacuum conditions. A hydration effect would destroy the hydrogen bonds within the

${ }^{a}$ School of Petroleum and Chemical Engineering, Dalian University of Technology, Panjin 124221, China. E-mail: hanrunlin@163.com; zhangshh@dlut.edu.cn; Fax: +86-4272631518; Tel: +86-13842712519

${ }^{b}$ State Key Laboratory of Fine Chemicals, Dalian University of Technology, Dalian 116024, China membrane and its layer spacing would become larger. Therefore, the separation performance of GO membrane would be unstable.

Zhang et al. developed a crosslinking method to enhance the flux of GO membranes without sacrificing the rejection rate. The GO-IPDI membrane exhibited a high flux of 80-100 L $\left(\mathrm{m}^{2} \mathrm{~h} \text { bar }\right)^{-1}$ under a low external pressure (1.0 bar). It exhibited a high rejection rate (above 96\%) for Congo red dye. ${ }^{13}$ Recently, a large family of 2D materials named 'MXene' has attracted significant research interest because they exhibit hydrophilic surfaces, good structural and chemical stability and excellent electrical conductivity. ${ }^{\mathbf{1 4 - 1 6}}$ MXenes are a type of layered 2D materials, which are often produced with MAX phase (where M represents an early transition metal, A corresponds to III A or IV A group elements, and $\mathrm{X}$ is $\mathrm{C}$ or $\mathrm{N}$ ) powders in HF solutions at ambient temperatures, followed by $\mathrm{Al}$ etching. Nowadays, $\mathrm{Ti}_{3} \mathrm{C}_{2} \mathrm{~T}_{x}$ (where $\mathrm{T}$ represents $\mathrm{O}, \mathrm{OH}$, and/or $\mathrm{F}$ groups while $x$ is the number of the terminating groups) is more commonly studied because it is easier to prepare; the synthesis involves etching $\mathrm{Ti}_{3} \mathrm{AlC}_{2}$ with $\mathrm{HF}$ at room temperature. Compared with GOs, MXene materials have superior chemical stability and thermal resistance. They have been widely utilized in the fabrication of super capacitors, ${ }^{17}$ lithium-ion batteries, ${ }^{18}$ and for heavy metal adsorption because of the layered structure of the MXene have large surface areas. ${ }^{19}$ Barsoum et al. prepared the polymer- $\mathrm{Ti}_{3} \mathrm{C}_{2} \mathrm{~T}_{x}$ composite nanofibers via electrospinning. ${ }^{20}$ Nanometer-thin sheets of $2 \mathrm{D}$ MXene were assembled into freestanding or supported membranes for the selective rejection of ions and molecules. Micrometer-thick MXene membranes demonstrated ultra-fast water flux of $37.4 \mathrm{~L}$ $\left(\mathrm{bar} \cdot \mathrm{h} \mathrm{m}^{2}\right)^{-1}$ and differential sieving of salts based on the 
hydration radius and charge of the ions. ${ }^{21} \mathrm{Wu}$ et al. used $\mathrm{Ti}_{3} \mathrm{C}_{2} \mathrm{~T}_{x}$ nanosheets as nanofillers to prepare a SRNF composite membrane. When this membrane was incorporated into two typical polymer matrixes, hydrophilic polyethyleneimine (PEI) and hydrophobic polydimethylsiloxane (PDMS), the uniformly dispersed $\mathrm{Ti}_{3} \mathrm{C}_{2} \mathrm{~T}_{x}$ nanosheets enhanced the thermal/ mechanical stabilities and solvent resistance of the polymerbased membranes. ${ }^{22}$ Wang et al. proposed a type of $2 \mathrm{D}$ lamellar membrane consisting of $\mathrm{Ti}_{3} \mathrm{C}_{2} \mathrm{~T}_{x}$ MXene nanosheets and nanosized $\mathrm{Fe}(\mathrm{OH})_{3}$ supported on an anode, aluminum oxide (AAO) substrate. The MXene membrane with an extremely short transport pathway and large amounts of nanochannels showed excellent water permeance (more than $1000 \mathrm{~L} \mathrm{~m}^{-2} \mathrm{~h}^{-1}$ ) and a favorable rejection rate (over 90\%) for molecules with sizes around $2.5 \mathrm{~nm}$ using a filter flask under a vacuum of $0.1 \mathrm{MPa}{ }^{23}$ Herein, the $\mathrm{Ti}_{3} \mathrm{C}_{2} \mathrm{~T}_{x}$ was produced by etching and ultrasonication of $\mathrm{Ti}_{3} \mathrm{AlC}_{2}$ and utilized to prepare the MXene composite membrane by a simple filtration method at $0.5 \mathrm{MPa}$ on a flexible polyethersulfone (PES) ultrafiltration membrane, thus broadening the range of application. The prepared membrane has extremely high flux and high rejection to Congo red dye. Simultaneously, the membrane preparation process can be easily scaled up and the functional layer is very stable to hydraulic flush.

\section{Experimental}

\subsection{Materials and instruments}

The average particle size of the $\mathrm{Ti}_{3} \mathrm{AlC}_{2}$ used in the experiment is about $3 \mu \mathrm{m}$ (98\%, Beijing Fusiman). A PES ultrafiltration membrane with MWCO (10 000) was prepared using the phase inversion method. The concentration of the hydrofluoric acid (HF) solution used was $49 \mathrm{wt} \%$ (Aladdin). All other chemicals were of analytical grade and used without further purification.

\subsection{Membrane preparation}

The $\mathrm{Ti}_{3} \mathrm{C}_{2} \mathrm{~T}_{x}$ was produced by etching of $\mathrm{Ti}_{3} \mathrm{AlC}_{2}$ with $49 \% \mathrm{HF}$ at $50{ }^{\circ} \mathrm{C}$ for $4 \mathrm{~h}$, followed by filtration. Then, the filtrate was neutralized to at least pH 6 and dried in the air at room temperature. Further, it was delaminated in DMSO via ultrasonication for $20 \mathrm{~h}$. Then, the solution was diluted to $1 \mathrm{~g} \mathrm{~L}^{-1}$ and filtered through a PES UF membrane in a dead-end membrane set-up. The filtration was processed at $0.2 \mathrm{MPa}$ with continuous stirring. The membrane area was determined to be $48 \mathrm{~cm}^{2}$ and the influences on the membrane performance and morphology were studied by adjusting the MXene content.

\subsection{Membrane characterization}

The performances of the membranes are primarily described by their product water flux, $J$, and rejection, $R$. The membranes were characterized in a dead-end membrane module after they were pretreated under a pressure of $0.3 \mathrm{MPa}$ for $30 \mathrm{~min}$. The membrane performances including water flux, salt rejection $\left(1 \mathrm{~g} \mathrm{~L}^{-1}\right)$ and dye rejection (100 ppm) were measured under a pressure of $0.2 \mathrm{MPa}$ at $20{ }^{\circ} \mathrm{C}$. The permeation flux, $F\left(\mathrm{~L} \mathrm{~m}^{-2} \mathrm{~h}^{-1}\right)$, is calculated as follows:

$$
F=\frac{V}{A t},
$$

where $V$ is the total volume of the water or solution permeated during the experiment; $A\left(\mathrm{~m}^{2}\right)$ is the membrane area; and $t(\mathrm{~h})$ is the operation time. Rejection, $R$, is calculated using the following equation:

$$
R=\left(1-\frac{C_{\mathrm{p}}}{C_{\mathrm{f}}}\right) \%
$$

where $C_{\mathrm{p}}\left(\mathrm{g} \mathrm{L}^{-1}\right)$ and $C_{\mathrm{f}}\left(\mathrm{g} \mathrm{L}^{-1}\right)$ are the concentrations of the permeate solution and the feed solution, respectively. All the experiments to determine flux and rejection were repeated three times. The relation standard deviation of the data was lower
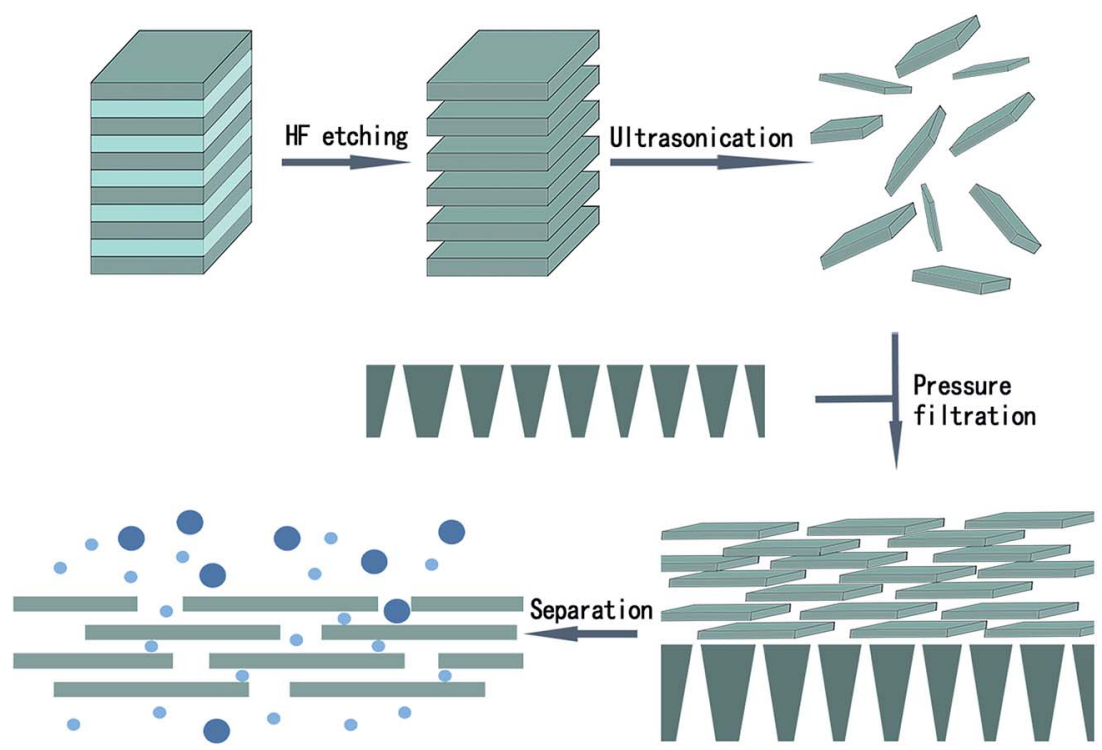

Fig. 1 Schematic of the preparation and separation of the MXene/PES composite membrane. 
than $15 \%$. The contact angle of the membrane surface was tested with a contact angle meter (WCA, SL200KB). Membrane rejection was tested with a conductivity meter (DDS-11A, Shanghai rex electric chemical instrument co., LTD) and UVvis Spectrophotometer (721, Shanghai Youke). The material and membrane morphology was observed using scanning electronic microscopy (SEM, NanoSEM 450, FEI), and main elements were detected using INCA EDX.

\section{Results and discussion}

\subsection{Characterization of the membrane material MXene}

The $\mathrm{Ti}_{3} \mathrm{C}_{2} \mathrm{~T}_{x}$ was produced by etching $\mathrm{Ti}_{3} \mathrm{AlC}_{2}$ with $40 \% \mathrm{HF}$ at room temperature for $12 \mathrm{~h}$, followed by filtration. Then, the filtrate was neutralized to at least $\mathrm{pH} 6$ and dried in the air at room temperature. The $\mathrm{Ti}_{3} \mathrm{C}_{2} \mathrm{~T}_{x}$ was filtered through a PES membrane supported with a non-woven fabric to obtain MXene/ PES composite membrane as shown in Fig. 1.

The morphology of the material was observed using SEM (Fig. 2). The particles of $\mathrm{Ti}_{3} \mathrm{AlC}_{2}$ are very dense with layered structures and the layers are clearly connected. Following treatment, the $\mathrm{Al}$ layer of $\mathrm{Ti}_{3} \mathrm{AlC}_{2}$ was reacted with $\mathrm{HF}$. It can be observed that the lamellar $\mathrm{Ti}_{3} \mathrm{C}_{2} \mathrm{~T}_{x}$ was successfully produced with enlarged interplanar spacing.

EDS results, indicating the variation in $\mathrm{Al} / \mathrm{Ti}$ atomic ratio, is another powerful evidence reflecting etching effect. As shown in Fig. 2, the amount of elemental Al decreased clearly after the treatment with $\mathrm{HF}$. The $\mathrm{Al} / \mathrm{Ti}$ atomic ratio declined from 0.7 to
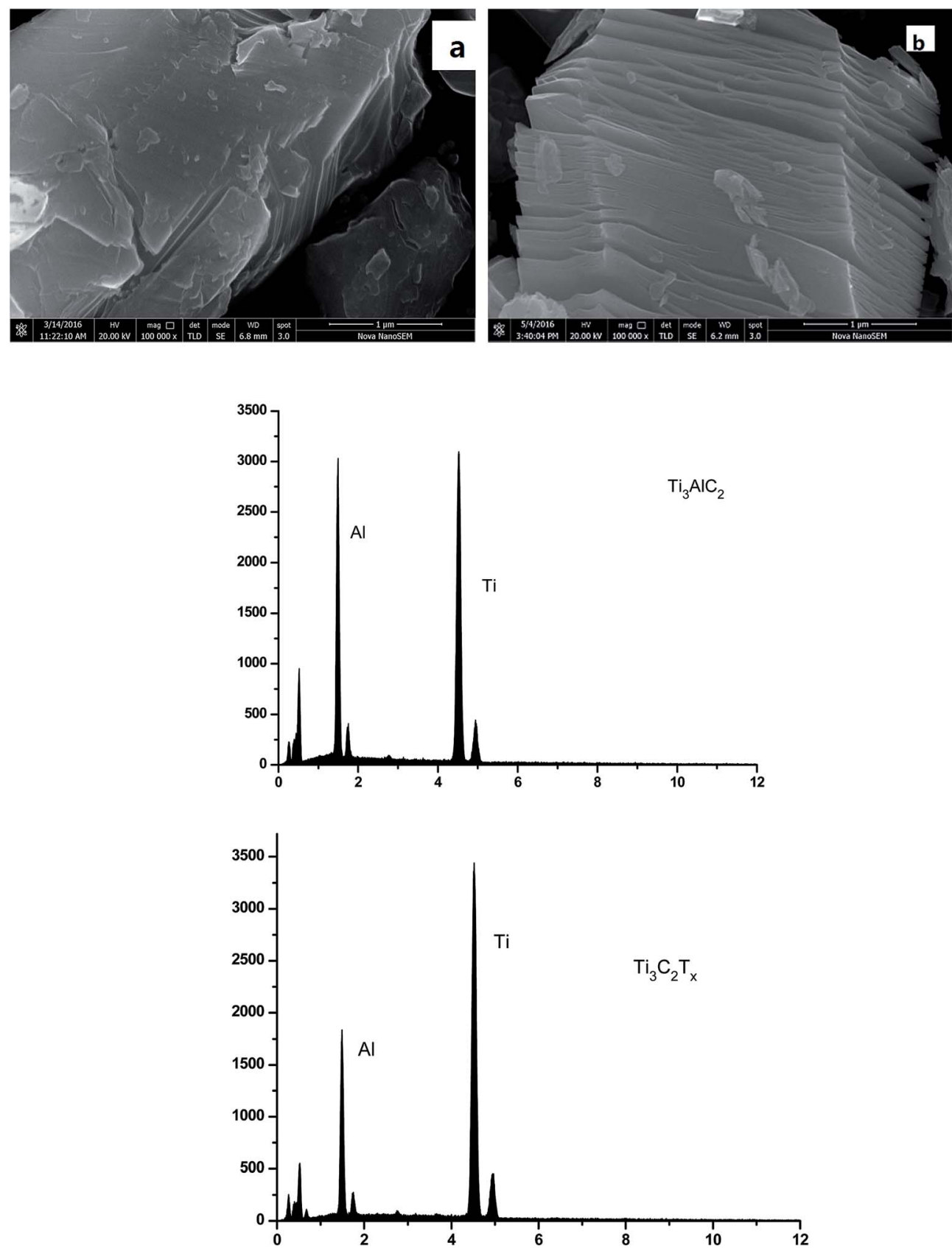

Fig. 2 The morphology and EDS image of the materials: (a) $\mathrm{Ti}_{3} \mathrm{AlC}_{2}$; (b) $\mathrm{Ti}_{3} \mathrm{C}_{2} \mathrm{~T}_{x}$. 
Table 1 Substance constitution and contact angle of the composite membrane

\begin{tabular}{llllll}
\hline Membrane & M0 & M1 & M2 & M3 & M4 \\
\hline MXene content/g $^{\text {Contact angle/ }}{ }^{\circ}$ & 0 & 0.1 & 0.15 & 0.2 & 0.25 \\
& 89 & 0 & 0 & 0 & 0
\end{tabular}

about 0.41 after treatment, indicating the etching of the $\mathrm{Al}$ from $\mathrm{Ti}_{3} \mathrm{AlC}_{2}$.

\subsection{Characterization of the as-prepared MXene composite membrane}

In order to prepare the MXene/PES composite membrane, MXene was delaminated in DMSO via ultrasonication for
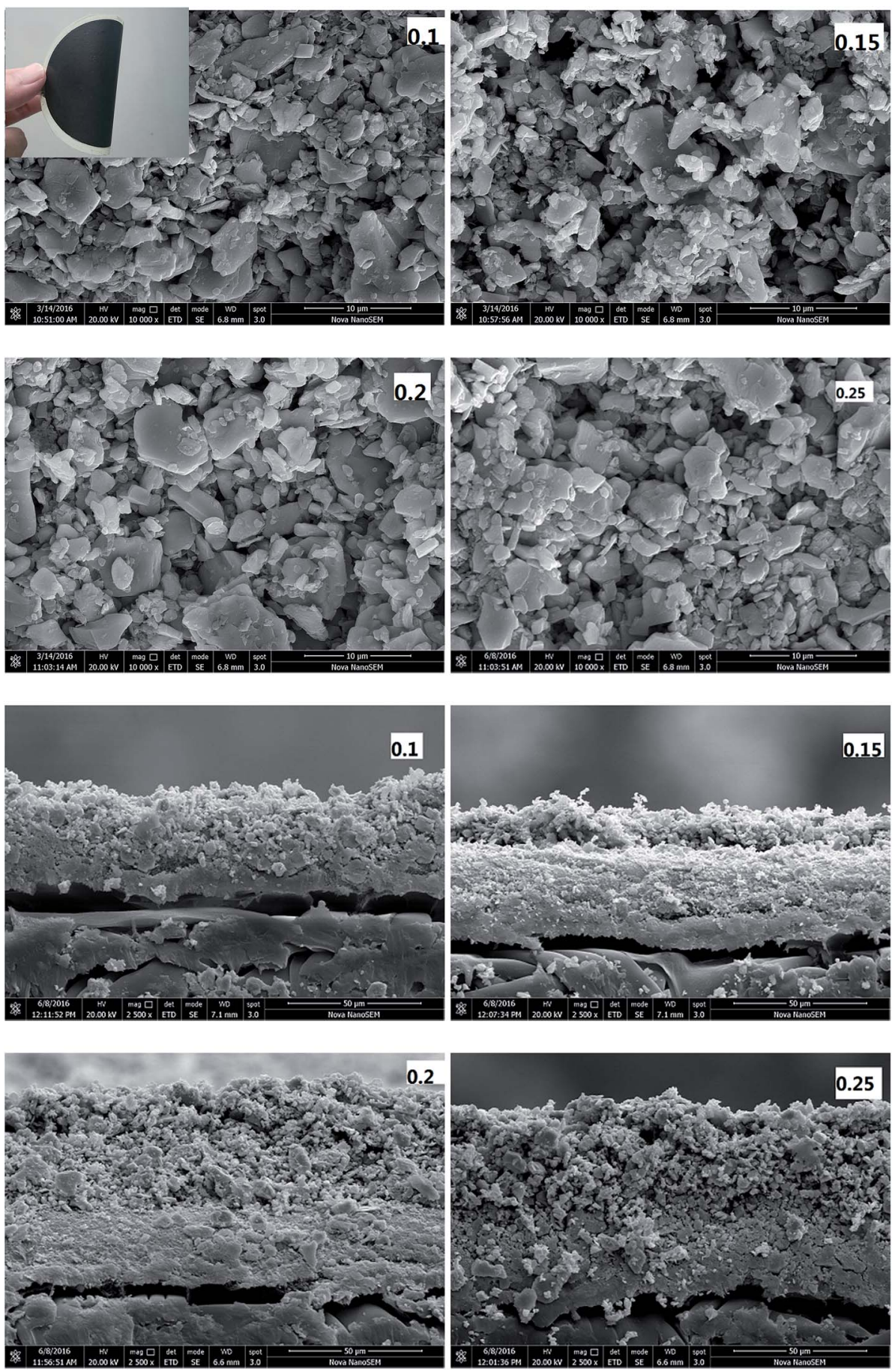

Fig. 3 The top surface and cross-section morphology of the prepared MXene/PES composite membrane: 0.1, the MXene membrane prepared with $0.1 \mathrm{~g} \mathrm{Ti}_{3} \mathrm{C}_{2} \mathrm{~T}_{x}$; the inset is the top surface morphology of the membrane; 0.15 , the MXene membrane prepared with $0.15 \mathrm{~g} \mathrm{Ti}_{3} \mathrm{C}_{2} \mathrm{~T}_{x} ; 0.2$, the MXene membrane prepared with $0.2 \mathrm{~g} \mathrm{Ti}_{3} \mathrm{C}_{2} \mathrm{~T}_{x} ; 0.25$, the MXene membrane prepared with $0.25 \mathrm{~g} \mathrm{Ti}_{3} \mathrm{C}_{2} \mathrm{~T}_{x}$. 

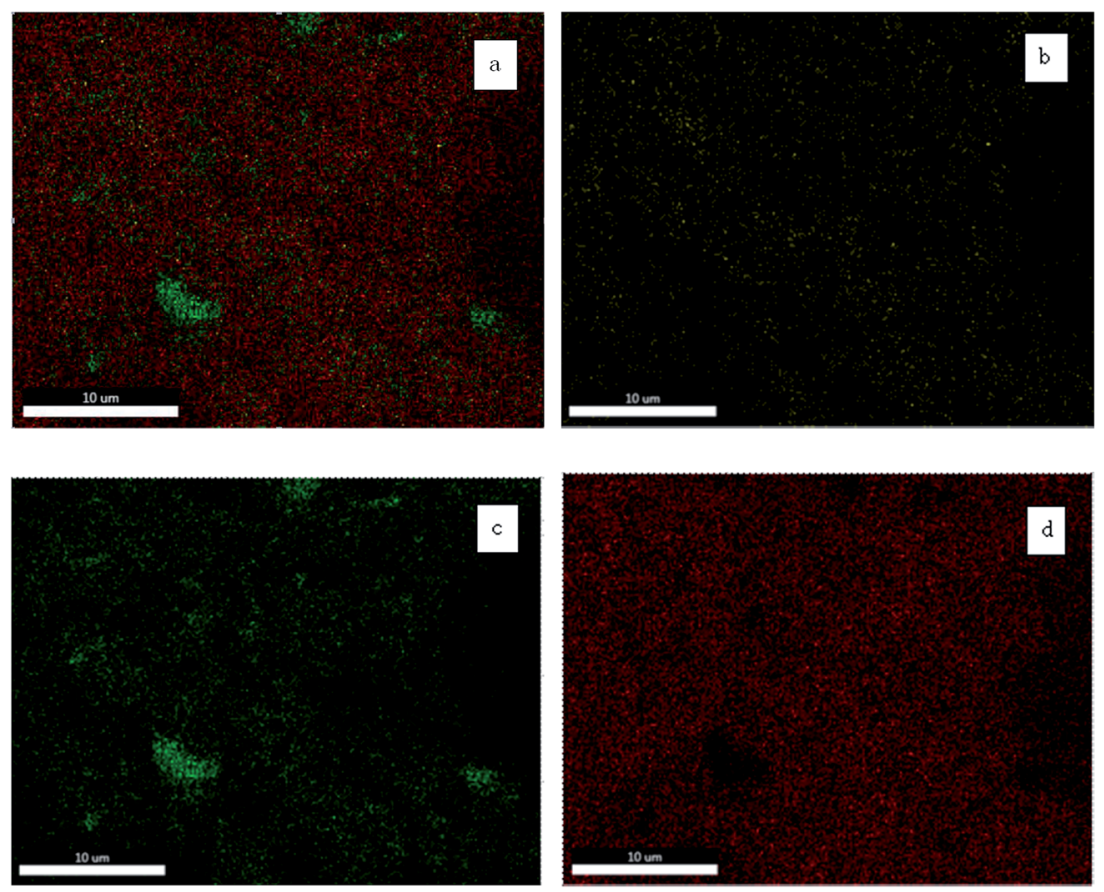

Fig. 4 The elemental maps of EDS of M3 with the same scale bar: (a) C, Al and Ti; (b) C; (c) Al; (d) Ti.

$20 \mathrm{~h}$. Then, the solution was diluted to $1 \mathrm{~g} \mathrm{~L}^{-1}$ and filtered through a PES UF membrane at $0.2 \mathrm{MPa}$ with continuous stirring. The membranes were prepared with different content of MXene. The constitution and contact angle of the membrane are listed in Table 1. It is found that the water drop would immediately spread over the membrane surface. This could occur because the MXene has excellent hydrophilicity for the $-\mathrm{OH}$ group and the nano-sized channels in the MXene sheets would absorb significant amounts of water.

The morphologies of the composite membranes are shown in Fig. 3. The composite membranes display good flexibility and the functional layer would not peel off the support membrane under ambient temperature. The top surface of the composite membrane, under $10000 \times$ magnification, reveals the rough structure. Most of the particles are closely stacked, inferring the good permselectivity of the composite membrane. With an increase in MXene content, the morphology changes slightly since the same membrane material is used. As shown in Fig. 3, the inorganic particles are stacked within the surface of PES membrane with the non-woven fabric. The thickness of the functional layer is increased, which, in turn, increases the mass transfer resistance and decreases the defects of the composite membrane.

The membrane top surface of M3 was scanned by EDX and the elemental maps are shown in Fig. 4. The elemental maps show that all elements are distributed homogeneously with the content of element $\mathrm{Ti}$ shown to be sufficient. $\mathrm{Al}$ is also observed in the elemental map probably because the inner $\mathrm{Al}$ was not completely etched by the HF due to its low concentration.

\subsection{The performance of the MXene composite membrane}

As shown in Fig. 5, the performance of membranes with different MXene contents was investigated and along with that of the supporting membrane. The $100 \mathrm{ppm}$ Congo red dye (697 Da) solution was used as the testing solution. The supporting membrane has a rejection of $10.7 \%$ to the dye and the flux is about $114.9 \mathrm{~L} \mathrm{~m}^{-2} \mathrm{~h}^{-1}$ at $0.1 \mathrm{MPa}$. With the increase in MXene content, the rejection to dye clearly elevated; the membrane flux initially increases and then declines. The supporting membrane possesses satisfactory rejection to dye and low flux. This can be interpreted by the hydrophobic nature of the membrane causing the adsorption of the dye molecules to reduce the flux of the membrane. The introduction of MXene particles into the membrane surface improves the hydrophilicity of the

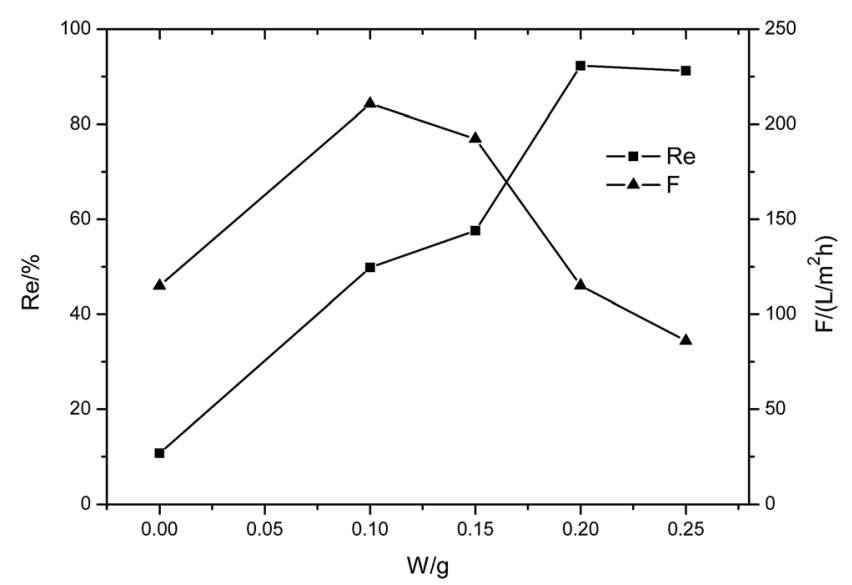

Fig. 5 The performance of the MXene membrane with different MXene contents (100 ppm Congo red dye, 0.1 MPa). 


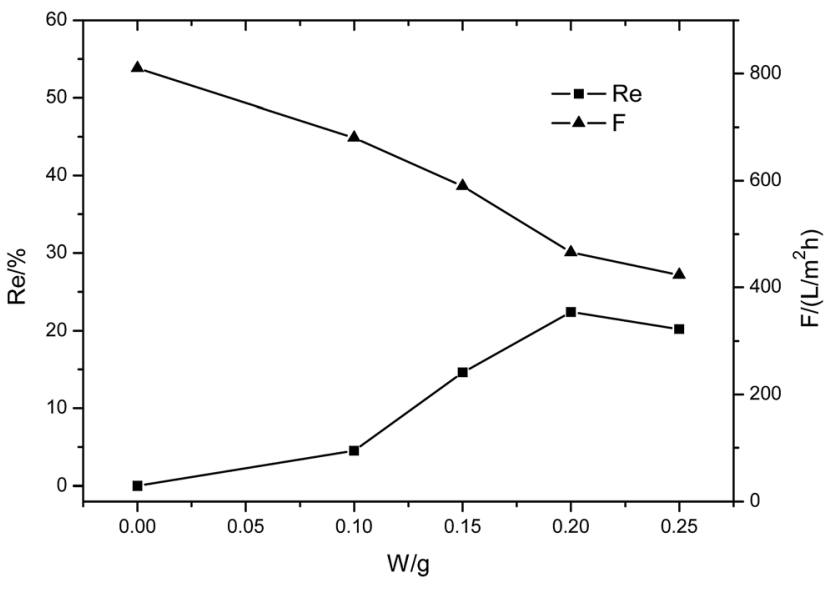

Fig. 6 The performance of the MXene membrane with different MXene contents ( $1 \mathrm{~g} \mathrm{~L}^{-1} \mathrm{MgCl}_{2}$ solution, $\left.0.1 \mathrm{MPa}\right)$.

membrane and significantly lowers the membrane fouling. Only a few dye molecules are adsorbed in the membrane pores. Therefore, the membrane flux initially improves. With a further increase in MXene content, the resistance of mass transfer increases and the membrane flux is decreases. When the MXene content is increased to $0.2 \mathrm{~g}$, the membrane shows high rejection $(92.3 \%)$ and high flux $\left(115 \mathrm{~L} \mathrm{~m}^{-2} \mathrm{~h}^{-1}\right)$ due to the dense and defect-free functional layer (Fig. 6-8).

The membranes were also tested with $1 \mathrm{~g} \mathrm{~L}^{-1} \mathrm{MgCl}_{2}$ solution at $0.1 \mathrm{MPa}$. It was found that the supporting membrane has no rejection to the inorganic salt $\mathrm{MgCl}_{2}$ and the membrane flux is very high (about $810 \mathrm{~L} \mathrm{~m}^{-2} \mathrm{~h}^{-1}$ ). When MXene was introduced in the membrane surface, the rejection to $\mathrm{MgCl}_{2}$ increased, but remained below $23 \%$, while the flux clearly declined with MXene content. At the same operating pressure, the membrane flux for $\mathrm{MgCl}_{2}$ is about 4 to 6 times that tested with the dye solution. This phenomenon is common because the dye molecules would accumulate in the membrane pores, thus improving the flow resistance substantially. The high flux of the composite membrane indicates that the MXene membrane

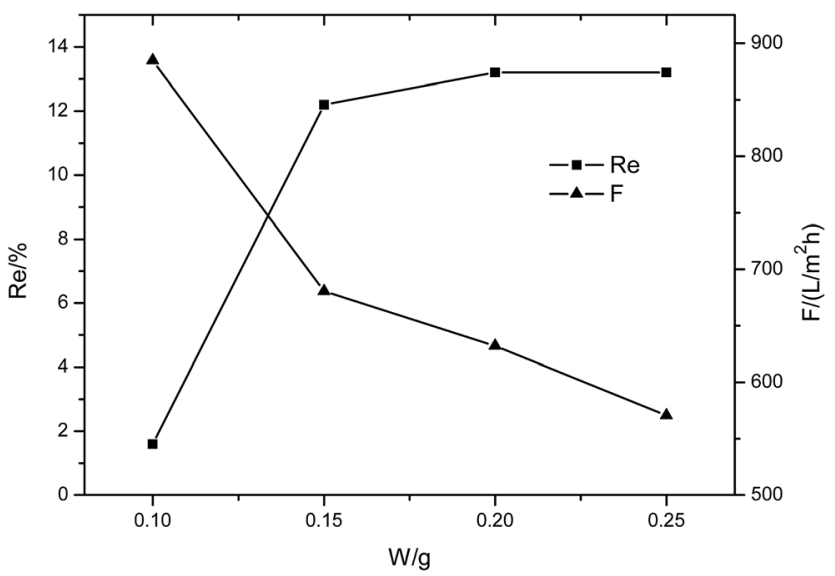

Fig. 7 The performance of the MXene membrane with different MXene contents ( $1 \mathrm{~g} \mathrm{~L}^{-1} \mathrm{Na}_{2} \mathrm{SO}_{4}$ solution, $0.1 \mathrm{MPa}$ ).

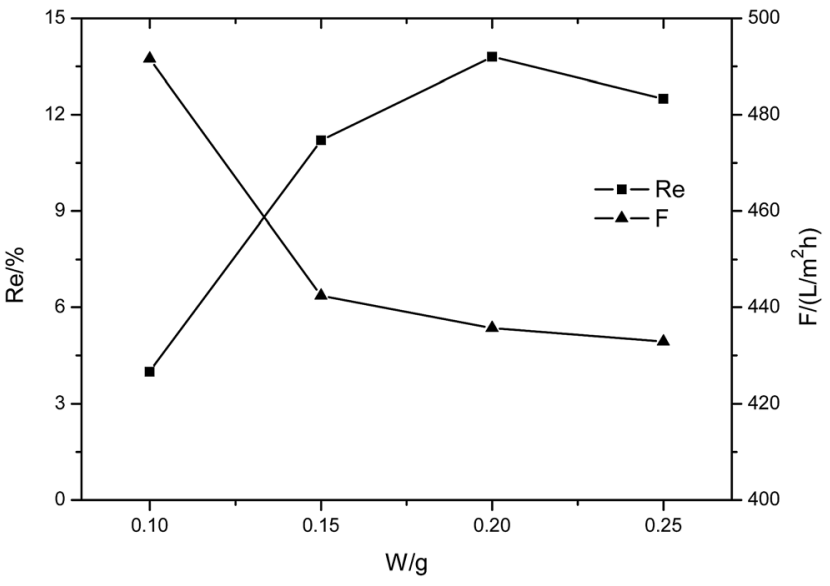

Fig. 8 The performance of the MXene membrane with different MXene contents ( $1 \mathrm{~g} \mathrm{~L}^{-1} \mathrm{NaCl}$ solution, $\left.0.1 \mathrm{MPa}\right)$.

Table 2 Performance of the MXene composite membrane with $0.2 \mathrm{~g}$ MXene (0.1 MPa)

\begin{tabular}{llllll}
\hline Feed & $\begin{array}{l}\text { Congo } \\
\text { red }\end{array}$ & Gentian violet & $\mathrm{MgCl}_{2}$ & $\mathrm{Na}_{2} \mathrm{SO}_{4}$ & $\mathrm{NaCl}$ \\
\hline$F\left(\mathrm{~L} \mathrm{~m}^{-2} \mathrm{~h}^{-1}\right)$ & 115 & 117.6 & 460 & 632 & 435 \\
$R(\%)$ & 92.3 & 80.3 & 23 & 13.2 & 13.8
\end{tabular}

exhibits a very loose lamellar structure, which provides a good flow channel for the solution.

The membranes were further tested with $\mathrm{Na}_{2} \mathrm{SO}_{4}$ and $\mathrm{NaCl}$ solutions to analyze the separation performance of the composite membrane. The membranes showed high flux (above $432 \mathrm{~L} \mathrm{~m}^{-2} \mathrm{~h}^{-1}$ ) and low rejection to inorganic salts at 0.1 MPa. The flux decreases and rejection to salts increases with an increase in MXene content.

The MXene composite membrane prepared with $0.2 \mathrm{~g}$ MXene has relatively high permselectivity. Therefore, it was tested with another dye, Gentian violet (408 Da). In this case, the membrane also showed high rejection $(80.3 \%)$ and flux (about $117.6 \mathrm{~L} \mathrm{~m}^{-2} \mathrm{~h}^{-1}$ ). As shown in Table 2, the membrane demonstrates large difference in the rejection of the dye molecule and that of the inorganic salt. Therefore, it is very highly suitable for dye desalination and wastewater treatment.

\section{Conclusions}

In conclusion, a type of a 2D MXene/PES composite membrane based on stacks of MXene nanosheets was prepared successfully by filtration on a PES UF membrane at $0.2 \mathrm{MPa}$. The membrane material was characterized using SEM and EDX. The prepared $\mathrm{Ti}_{3} \mathrm{C}_{2} \mathrm{~T}_{x}$ has a delaminated structure and a low $\mathrm{Al} / \mathrm{Ti}$ ratio after $\mathrm{HF}$ etching. The MXene membranes have rough and dense surface layers and uniform element distributions. The MXene membrane exhibits an increased rejection to dyes and inorganic salts with the increase in MXene content. When the MXene is 
fixed at $0.2 \mathrm{~g}$, the membrane shows high rejections to Congo red dye $(92.3 \%)$ and Gentian violet $(80.3 \%)$ and high flux (above $115 \mathrm{~L} \mathrm{~m}^{-2} \mathrm{~h}^{-1}$ ) at $0.1 \mathrm{MPa}$. The membrane's rejection to inorganic salts is below $23 \%$ with flux above $432 \mathrm{~L} \mathrm{~m}^{-2} \mathrm{~h}^{-1}$ at $0.1 \mathrm{MPa}$, which indicates that the membrane can be used with extremely high efficiency in dye desalination and wastewater treatment.

\section{Conflicts of interest}

There are no conflicts to declare.

\section{Acknowledgements}

The authors wish to thank the support of Natural Science Foundation of China (No: 51503089), the Fundamental Research Funds for the Central Universities (DUT16RC(3)049), the State Key Laboratory of Fine Chemicals (KF 1402).

\section{References}

1 I. G. Wenten and Khoiruddin, Reverse osmosis applications: Prospect and challenges, Desalination, 2016, 391, 112-125.

2 Y. Yao, C. Ba, S. Zhao, W. Zheng and J. Economy, Development of a positively charged nanofiltration membrane for use in organic solvents, J. Membr. Sci., 2016, 520, 832-839.

3 K. Vanherck, G. Koeckelberghs and I. F. J. Vankelecom, Crosslinking polyimides for membrane applications: a review, Prog. Polym. Sci., 2013, 38, 874-896.

4 Y. Liu, H. Huang, P. Huo and J. Gu, Exploration of zwitterionic cellulose acetate antifouling ultrafiltration membrane for bovine serum albumin (BSA) separation, Carbohydr. Polym., 2017, 165, 266-275.

5 B. M. Ganesh, A. M. Isloor and A. F. Ismail, Enhanced hydrophilicity and salt rejection study of graphene oxidepolysulfone mixed matrix membrane, Desalination, 2013, 313, 199-207.

6 X.-H. Ma, Z. Yang, Z.-K. Yao, Z.-L. Xu and C. Y. Tang, A facile preparation of novel positively charged MOF/chitosan nanofiltration membranes, J. Membr. Sci., 2017, 525, 269276.

7 R. Zhang, S. Ji, N. Wang, L. Wang, G. Zhang and J. R. Li, Coordination-driven in situ self-assembly strategy for the preparation of metal-organic framework hybrid membranes, Angew. Chem., Int. Ed., 2014, 53, 9775-9779.

8 R. Lin, L. Ge, S. Liu, V. Rudolph and Z. Zhu, Mixed-matrix membranes with metal-organic framework-decorated CNT fillers for efficient $\mathrm{CO}_{2}$ separation, ACS Appl. Mater. Interfaces, 2015, 7, 14750-14757.

9 R. K. Joshi, P. Carbone, F. C. Wang, V. G. Kravets, Y. Su, I. V. Grigorieva, H. A. Wu, A. K. Geim and R. R. Nair, Precise and Ultrafast Molecular Sieving Through Graphene Oxide Membranes, Science, 2014, 343, 752-754.

10 K. Huang, G. Liu, Y. Lou, Z. Dong, J. Shen and W. Jin, A Graphene Oxide Membrane with Highly Selective
Molecular Separation of Aqueous Organic Solution, Angew. Chem., Int. Ed., 2014, 53, 6929-6932.

11 Q. Zhao, J. Hou, J. Shen, J. Liu and Y. Zhang, Long-lasting antibacterial behavior of a novel mixed matrix water purification membrane, J. Mater. Chem. A, 2015, 3, 1869618705.

12 J. Zhu, M. Tian, J. Hou, J. Wang, J. Lin, Y. Zhang, J. Liu and B. Van der Bruggen, Surface zwitterionic functionalized graphene oxide for a novel loose nanofiltration membrane, J. Mater. Chem. A, 2016, 4, 1980-1990.

13 P. Zhang, J. L. Gong, G. M. Zeng, C. H. Deng, H. C. Yang, H. Y. Liu and S. Y. Huan, Cross-linking to prepare composite graphene oxide-framework membranes with high-flux for dyes and heavy metal ions removal, Chem. Eng. J., 2017, 322, 657-666.

14 M. Naguib, M. Kurtoglu, V. Presser, J. Lu, J. Niu, M. Heon, L. Hultman, Y. Gogotsi and M. W. Barsoum, Twodimensional nanocrystals produced by exfoliation of $\mathrm{Ti}_{3} \mathrm{AlC}_{2}$, Adv. Mater., 2011, 23, 4248-4253.

15 M. Naguib, J. Come, B. Dyatkin, V. Presser, P.-L. Taberna, P. Simon, M. W. Barsoum and Y. Gogotsi, MXene: a promising transition metal carbide anode for lithium-ion batteries, Electrochem. Commun., 2012, 16, 61-64.

16 A. Feng, Y. Yua, F. Jiang, Y. Wang, L. Mi, Y. Yu and L. Song, Fabrication and thermal stability of $\mathrm{NH}_{4} \mathrm{HF}_{2}$-etched $\mathrm{Ti}_{3} \mathrm{C}_{2}$ MXene, Ceram. Int., 2017, 43, 6322-6328.

17 Z. Ling, C. E. Ren, M.-Q. Zhao, J. Yang, J. M. Giammarco, J. Qiu, M. W. Barsoum and Y. Gogotsi, Flexible and conductive MXene films and nanocomposites with high capacitance, Proc. Natl. Acad. Sci. U. S. A., 2014, 111, 16676-16681.

18 M. Naguib, J. Come, B. Dyatkin, V. Presser, P.-L. Taberna, P. Simon, M. W. Barsoum and Y. Gogots, MXene: a promising transition metal carbide anode for lithium-ion batteries, Electrochem. Commun., 2012, 16, 61-64.

19 O. Mashtalir, K. M. Cook, V. N. Mochalin, M. Crowe, M. W. Barsoum and Y. Gogotsi, Dye adsorption and decomposition on two-dimensional titanium carbide in aqueous media, J. Mater. Chem. A, 2014, 2, 14334-14338.

20 E. A. Mayerberger, O. Urbanek, R. M. McDaniel, R. M. Street, M. W. Barsoum and C. L. Schauer, Preparation and characterization of polymer- $\mathrm{Ti}_{3} \mathrm{C}_{2} \mathrm{~T}_{\mathrm{x}}$ (MXene) composite nanofibers produced via electrospinning, J. Appl. Polym. Sci., 2017, 134, 1-7.

21 C. E. Ren, K. B. Hatzell, M. Alhabeb, Z. Ling, K. A. Mahmoud and Y. Gogotsi, Charge- and Size-Selective Ion Sieving Through $\mathrm{Ti}_{3} \mathrm{C}_{2} \mathrm{~T}_{x}$ MXene Membranes, J. Phys. Chem. Lett., 2015, 6, 4026-4031.

$22 \mathrm{X} . \mathrm{Wu}, \mathrm{L}$. Hao, J. Zhang, X. Zhang, J. Wang and J. Liu, Polymer- $\mathrm{Ti}_{3} \mathrm{C}_{2} \mathrm{~T}_{\mathrm{x}}$ composite membranes to overcome the trade-off in solvent resistant nanofiltration for alcoholbased system, J. Membr. Sci., 2016, 515, 175-188.

23 L. Ding, Y. Wei, Y. Wang, H. Chen, J. Caro and H. Wang, A Two-Dimensional Lamellar Membrane: MXene Nanosheet Stacks, Angew. Chem., Int. Ed., 2017, 56, 1825-1829. 